a machine from a nose dive without allowing a considerable time to get the focus, otherwise they will misjudge the distance and crash their machine.

Let me take this opportunity to thank Col. J. T. Fotheringham, D. M. S., and J'rofessor J. M. McCallum for the opportunity of studying these cases in the military clinic at the Toronto icneral Hospital.

\section{BILATERAL SUBCONJUNCTIVAL HEMORRHAGES.}

Dr. Francisco M. Fernandiz.

ILAVANA, CUBA.

This case is a trivial one and would not have been published had it not some curion: features that may make it worthy of mention.

A young man, 26 years old, consulted us, becaluse during the first days of January, 1919, he noticed some small blood spoits in his eyes.

On examination we saw very numerous hemorrhagic foci, studding both bulbar conjunctiva the size of a millet grain, numbering from 20 to 30 in each eyc. The hemorrhagic spots were also present in large numbers in both lower conjunctivae, the upper ones being free from any spots.

The history of the case was negative of any traumatism, lifting heavy weiglts, cough or vomiting, and the possible explanation of the cause was that the patient had been crying excessively several days previously, on account of the death of his father.

The clement of surprise in this case is the possible etiologic factor, and the large number of hemorrhagic foci, as well as the occurrence in both eyes, in a symmetric formation.

\title{
SOCIETY PROCEEDINGS
}

\section{ROYAL SOCIETY OF MEDICINE, SECTION OF OPHTHAL- MOLOGY.}

\author{
March 28, 1919.
}

Mr. W. T. Holmes Spiclek, President.

\section{Angioid Streaks in Retina.}

Mr. Elmore Brewfrton exhibited a patient whose retina presented a peculiar serics of angioid streaks. He brought the case because of the extensive character of the change. Tho the condition seemed to be rare, he understood Mr. Spicer had seen the appearance in more than one of his cases. ( )n looking into the literature, he founcl that Ward Holden attributed such streaks to the remains of diffuse hemorrhage in a linear direction, thru the layers of the retina. But the exhibitor could not imagine blood to follow such lines, except in the nerve fibre layer, and these streaks were not in that, but posterior to it.

W. T. Lister believed the streaks to be vestiges of new vessels along whose course were arranged exudates which had undergone secondary pigmentation. The streaks in this case, however, Mr. Brewerton did not think were new vesscls, as, in the left eye, they met in a lake or pool around the disc, and one could not think of a vessel extencling all the way around the disc. In a case reported by Zentmayer that nbscrver said an extravasation of blood was present while the streaks were visible. His own view was that the streaks were the remains of hemorrlage between retina and choroid. Their brown color reminded him of hematin.

The President did not think any explanation yet given of these appearances was satisfactory. He had a brother and sister with an identical condition, except that the pigmentation in those was more marked than in Mr. Brewerton's case. All four eyes of those two patients were involved in the same way. In them, it seemed im- 